\title{
Famine and its Causes in the Perspective of the Modern Geographical Thoughts
}

\author{
Degefa Tolossa *
}

\begin{abstract}
The paper argues that famine researches, based on various philosophies of contemporary geography would generate knowledge with different perspectives. Positivists mainly seek to identify factors that induce famine. An in-depth understanding of the processes of famine must rely upon humanists' approaches. In cases where investigations on famines are made in regard to poverty alleviation through empowering the poor and other marginal segments of a society, structuralism approaches become the most appropriate. It is concluded that famine being a multi-faceted socio-economic problem, and hence a research depending on single philosophical underpinning cannot come out with comprehensive knowledge of it. Therefore, a research project that entertains positivists, humanists and structuralists at a time can come up with somehow complete insights and observations, which in turn enable to prevent citizens from the agony of hunger and eradicate famine.
\end{abstract}

Key words: Famine, Geography, Humanism, Positivism and Structuralism.

\section{Introduction}

Famine as a socio-economic problem of human beings has a long history. The earliest recorded famine occurred in ancient Egypt around 4000 B.C (Johnston et al. 2000). Evidences show that although in varying magnitudes, only a few countries of the world could escape famine and starvation and the subsequent excessive mortalities of their citizens. Among the disastrous recorded famines were: UK (1315-17), Scotland (1615-25), Germany (1772), Sweden (1799), China (1958-61), India (1943), Bangladesh (1974), Ethiopia (1972/73 \& 1984/85), Sudan/Darfur (1984/85) (Dando 1980; Sen 1981; Mesfin 1984; de Waal 1989; Newman 1990). The very sad thing about famine is its persistence at the beginning of the twenty-first century, as a result of which several millions of the world populations are suffering. This seems to be immoral, at least, for two reasons. First, the food available at global level can sufficiently feed every individual. Nevertheless, this has not been possible, mainly because of considerable inequalities in terms of access to resources and lack of capacity to utilize them, power imbalance (almost at all levels ranging from individual to nation-state) and the differences in opportunities and constraints around the world (Degefa 2005). Secondly, on the one hand, people in rich countries are seriously

*Assistant Professor of Geography and Development Studies, College of Development Studies (CDS), Addis Ababa University. 
concerned about the amount and types of nutrients in their daily meal (dieting), while the majority of the poor in developing countries are worried about how they can acquire the minimum daily food intake, on the other. The poor people always live with hunger and starvation. They lack both economic and political power. The considerably widening inequality gaps between the poor and the rich at various geographical scales clearly imply that the latter are so reluctant to put possible effort in reducing poverty which, in turn, could help in preventing and eradicating the crisis of famine.

It was estimated that the number of world population that subsisted under food shortage exceeded 800 million by 2000, the largest figure than ever in history. Around 280 million of this food insecure people lived in South Asia; 240 million in East Asia; 180 million in Sub-Saharan Africa, and the rest in Latin America, Middle East and North Africa (Pinstrup-Andersen \& Pandya-Lorch 2001:7).

The magnitude of famine and its root causes varies across regions, countries, communities and households. This would rightly indicate that famine has spatial dimension, which attracts the attention of geographers. Geographical study of famine has a paramount significance in terms of generating basic knowledge on the issue as well as in identifying practical implications for preventing it. However, due to the existence of a multiple of philosophies within the discipline of geography, famine as a socio-economic problem will be addressed from different perspectives. In contemporary geography, the existing philosophies are broadly grouped under three schools of thought, that is, positivism, humanism, and structuralism, which have distinct epistemology, ontology and methodology. The purpose of this paper is, therefore, to know what sorts of scientific knowledge can be generated when we apply the three main approaches of the philosophy of geography in investigating famine. It is assumed that examining famine under a framework of different approaches can come out with new insights and knowledge with different viewpoints. A comparative analysis of the approaches would be expected to identify the most appropriate methods that can diagnose the problem for seeking long lasting remedies.

\section{Conceptualizing Famine}

The concept of famine becomes very difficult to define precisely, due to a number of reasons. Firstly, famine is a complex socio-economic phenomenon. Second, suffering out of hunger, victims' responses to it, and its consequences are approached, perceived and understood differently by people with varying professional backgrounds as well as with diverse philosophical beliefs. Third, the degree of vulnerability differences to the crisis, which can be attributed to a multiple of circumstances, such as environmental setting (terrain, climate, soil, etc), economic status (rich and poor), type of occupation (farming, pastoralism, fishery, etc), place of residence (urban and rural), geographical scale (individual, household, community, region, country and the world). Fourth, the definition may also vary depending on who defines it, that is, the famine victims themselves (insider definition) or researcher and expert/technocrats (outsider definition). Nonetheless, aiming at clearing conceptual confusion, the following few paragraphs present some definitions from the viewpoints of insiders and outsiders, on the basis of which an attempt is made to propose a working definition. 


\subsection{Insiders' Definitions}

De Waal is the most critical writer on the insider- famine victim's perception of what famine is. He strongly argues that definitions by people who experience famines are fundamentally more accurate than those coined by researchers (de Waal 1989). The following are some of the insiders' definitions.

Curry (1978) presents people's definition in Bangladesh, "the culture defines three types of famine: scarcity is akal (when times are bad); famine is durvicka (when alms are scarce) and nationwide famine is mananthor (when the epoch changes).... These subtle terms contrast with the international definition accepted at the Swedish famine symposium: 'widespread food shortage leading to a significant regional rise in the death rates". Likewise, de Waal (1987: 257) describes the concept of famine in Darfur as primarily one of the destitution and not mortality and starvation. Europeans believe that famine implies death by starvation; Africans who are exposed to famine do not. The same author warns that a distinction should be made between famine that causes death and the one that does not.

Consistent with the above conceptions, a pastoralist in Niger replied to the question what is famine as follows: "no one died, but the price of millet rose. When the sack of millet costs 6000 francs, is not that a famine"(Laya 1975 cited in de Waal 1989:9). Referring to famine in India, Rangasami (1985) also puts "mortality is not a necessary condition of famine".

A study in four districts of Northwestern Ethiopia has assessed farmers' perception of the concept of famine. A respondent in Tach Gayint describes famine as follows: "we face famine during few months of every year, particularly in summer, when our home food supply dwindles, when market price of crop rises ... but without resulting in event of deaths from starvation, in most cases". Similarly, the focus group participants in Simada district agree on the concept of famine to mean "any time of the year when home production of the majority of farm households in a community are in short supply, and when there is no financial capacity to purchase grain from local markets” (Degefa 2000). The farmers further disclose that unless the harvest fully fails like the situation in seba sabat (1977 E.C which refers to famine crisis of 1984/85), widespread deaths directly caused by hunger are unlikely.

It is apparent that all insider definitions have one common notion that the prevalence of famine is not manifested in the immediate toll of excessive mortality. De Waal's argument would capture this issue "... the concept grows out of the actual experience of famine, and in neither case is there a positive criterion of measurable changes in food availability or death rates. Most importantly, neither of these concepts of famine uses the presence of deaths from starvation as a criterion at all” (de Waal 1989: 10).

Another important thing to be drawn from the victims' conception of famine is that it is the recurrent famine as a process, which increases the destitution of the most vulnerable groups and at the end can result in high rates of death rather than the occurrence of a single event at its outset. Here lies the basic contrast between insiders' and outsiders' definitions: "the former recognize widespread death as the end result of famine processes, while the latter see it as the beginnings" (Deveroux 1993). Therefore, famine is preventable 
if the victims' conception will be taken into account while designing early warning systems.

\subsection{Outsiders' Definitions}

Researchers' and professionals' definitions of famine are quite different from that of insiders, mainly due to the fact that the former are preoccupied by the purpose of research (investigation) as well as by disciplinary boundaries under which they attempt to operationalise their views. Moreover, in a biological sense, famine is one form of human suffering that directly affects a physiology and health of a victim, and hence those who have experienced it and those who have not will have completely different perceptions towards it. Devereux (1993) broadly categorizes the outsiders' definitions into three: those that assume famine results from a decline in the supply of food (food shortage); those based on food consumption deficiency (mass starvation); and those based on observed responses to widespread hunger (behavioral).

Dando (1980) considers food shortage as the main cause of famine while describing it "as a temporary, but severe, local shortage of food is called famine. It is generally the result of an almost complete crop failure in an area of subsistence or near subsistence farming". Another definition by Watts (1983) goes "a famine is food shortage leading to widespread death from starvation; famine is a societal crisis induced by the dissolution of the accustomed availability of, and access to, staple foods on a scale sufficient to cause starvation among a significant number of individuals".

The definitions by Dando and Watts have one major drawback in that both of them failed to address the possibility of overcoming local short supply by imports. They give special attention to production and food availability. Sen (1981) challenges those definitions arguing that famine can happen in a region/country where food supply is not a problem. His point of argument is that food shortage may be one of the causal factors leading up to famine; it is neither a necessary nor a sufficient condition for a famine to occur.

Some researchers consider the occurrence of famine in instances where deaths of a large number of people are observed as a consequence of widespread starvation. A good instance for this is the definition by Mesfin (1984:9) which puts famine "as a widespread, prolonged and persistent, extraordinary and insufferable hunger lasting for several months and affecting the majority of the rural population over a more or less extensive area, resulting in total social and economic disorganization and mass death by starvation”. The important point in this definition is that it equates famine with death excluding minor famines that affect millions of people almost every year on a regular basis with no death tolls.

Behavioral definitions are distinguished from other outsider conceptions due to the fact that the former focus on consequences and the responses at a community level. Behaviorists consider famine as a processes rather than event. In this regard, Curry (1978: 90) defines famine "as community syndrome, which results when social, economic and administrative structures are already under stress and are further triggered by one or several, discrete disruptions which accelerate the incidence of many symptoms, or crisis adjustment of which one is epidemic malnutrition”. The definition by Alamgir (1980) 
points out some of the social, economic and biological consequences: "famine is considered to represent a general state of prolonged food grain intake deficiency per capita giving rise to a number of accompanying substates (symptoms) involving individuals and the community that ultimately lead, directly or indirectly, to excess death in a region or a country as a whole”. The consequences of famine include: increase in interregional migration, increase in crime, increase in incidence of fatal diseases, loss of body weight, changes in nutritional status, eating of alternative 'famine' foods', mental disorientation, wandering, uprooting of families, separation of families, transfer of assets, and breakdown of traditional social bonds.

\subsection{Working Definitions}

An assessment of the existing definitions has enabled me to suggest an operational definition. Famine may be defined as a food shortage and the resultant hunger affecting people at various scales: individual (food deprivation), household (food poverty), and region (food shortage), due to either inability to produce sufficient food, or lack of sufficient money to buy food (lack of purchasing power). Famine can lead to serious environmental, economic and social disruptions. Its magnitude can considerably vary from one that may not cause death to one that results in excessive mortality.

It is also important to make the distinction between famine and food insecurity. Food insecurity is a situation in which the individuals of the society have neither the physical nor the economic access to the nourishment they need. Depending on temporal dimension, two types of household food insecurity can be distinguished: chronic and transitory food insecurity. Chronic (permanent) food insecurity refers to a continuously inadequate diet resulting from the lack of resources to produce or acquire food. Transitory food insecurity refers to a temporary decline in households' access to enough food. The severe form of transitory food insecurity is famine.

\section{Philosophies in Modern Geography}

Every field of study has its own philosophical foundation upon which inquires are made for further knowledge generation. In order to apply a specific philosophy in investigating a research problem, the prior task must be to thoroughly understand the essence of the philosophy itself. Kitchin and Tate (2000) suggest that understanding philosophical approaches is important for two principal reasons: first, it helps in understanding what other researchers have done and why; second, it helps in finding an approach on which to base your own research and provides the theoretical context in which to justify the findings.

A subject matter of a discipline would be one of the decisive factors for the type of philosophy to adopt in formulating research problem (questions of inquiry). This is because 'what we can know' and 'how we know' about the object (epistemology), 'what can be known or what can exist' (ontology), and the procedures to follow in research (methodology) constitute the three pillars of philosophy (Johnston 1983).

In broad sense, geography studies nature-society interrelations as a system. In the struggle to make livelihood, society shapes, alters and transforms the natural environment and creating partially or totally humanized landscapes. Conversely, nature influences the 
human being in a multitude of ways. These make the system of their interrelations quite complex, as a result of which the domain of geography is inevitably so wide. Emphasizing on the complex interrelations of nature and society and the challenges facing geographers in this regard, Peet (1998:2) argues "understanding this system of relations requires geographers to be sophisticated natural and social scientists, find ways of combining the two, know the methods and be excited by the insights of both aspects of knowledge". In favor of Peet's idea, Holt-Jensen (1999:2) describes geography as "a science of synthesis, a science linking humanity and environment and creating a bridge between the social and natural sciences".

At this point, it is important to briefly look into what is meant by the "philosophy of geography'. According to Peet (1998), the 'philosophy of geography' is the system of general ideas concerned with direction and content of geographical work, which the practitioners elaborate during practice. That is, teaching, writing and practicing geography at the level of exact theory leads to the formation of abstract notions which both summarize multiple relations or practical insights and project them in speculative ways into scarcely theorizing new directions'. At least, two important issues stand out. First, the philosophy of the discipline refers to the systematically abstracted ideas and notions of what geographers do. Second, the fact that geographers do practice a multitude of activities as well as geography's concern with extensively diverse phenomena, has partly contributed for the emergence of a variety of philosophical approaches within the discipline.

In response to the evolution of the phenomena studied in geography and the advance in the geographical knowledge, the philosophy of geography has depicted a considerable structural dynamism. According to Johnston (1991), change within the discipline involves both dissatisfaction with existing approaches and the preparation of acceptable alternative. In the twentieth century, the philosophy of geography became more a materialist history of real processes. In other words, there is a change in the purpose of thinking in general from spiritual contemplation to practical intellectual activity.

The dynamic nature of geographical thought over the century had been manifested in the emergence of a diversity of philosophies in the discipline. Kitchin and Tate (2000) identify 12 varieties of approaches that have been in use in geographical studies over a few decades. Some have little variations while others are extremely divergent in their approaches. As such, the typologies of philosophies in geography over the last fifty years were broadly put under three groups of approaches namely: positivists, humanists and structuralists (Johnston 1983). This classification appears to be consistent with Habermas' grouping of science into three variants: empirical-analytical, historical-hermeneutic and critical (Hebermas 1978 cited in Kitchin and Tate 2000). Habermas's theory suggests that these respective sciences generate three types of knowledge-constitutive interests: "knowledge which enables the human species to control objects in nature and thus produces necessities of its material existence (with social medium of work); knowledge which enables people to communicate (with social medium of language); and knowledge which enables the species to act rationally to be self-determining and self-reliance (with social medium of power)" (Habermas 1978 cited in Unwin 1992). In light of this, the paper examines how to study famine and its causes for generating knowledge that can serve for technical, practical and emancipatory purposes. 


\section{Positivism and Explaining Famine}

Positivism is a philosophy of science originally advanced by the French philosopher and sociologist Auguste Comte (1798 -1857) whose primary purpose was to distinguish science from both 'metaphysics' and 'religion'. Unwin (1992) notes that Comte used the term 'positive' to refer to the actual, the certain, the exact, the useful and the relative rather than the imaginary, the undecided, the imprecise, the vain and absolute. Thus, the epistemology of the positivism is that knowledge is gained through experience, but which requires that this experience to be firmly established as verifiable evidence on which all will agree. Its methodology calls for accurate observation and reportage.

Contemporary positivism consists of two versions: logical positivism and critical rationalism. The Vienna School initiated logical positivism, which is based on the idea of verification, in 1920 with the intention to combine British empiricism with traditional positivism (Holt-Jensen, 1999). The Vienna School defined precise scientific principles and used formal logic to verify theories and make statements of knowledge based upon the axioms produced. The formal laws constructed, in turn, led to formation of new questions to be verified against reality (Kitchin and Tate 2000).

Karl Popper introduced critical rationalism, as the other version of positivism. He argued that the truth of a law does not depend upon the number of times it is experimentally observed or verified, but rather on whether it can be falsified (Chalmers 1982). Scientific validation should not proceed along the lines of providing confirmatory evidences but rather by identifying circumstances, which may lead to the rejection of the theory.

The introduction of positivism into geography has coincided with the period known as 'quantitative revolution'. There was much concern about the descriptive nature of the discipline up to the late 1950s. As a result, there were advocates (Shaefer 1953, Harvey, 1969) of the need to adopt quantitative techniques that could enable geographers to scientifically explain the cause and effect relationship between various physical and cultural phenomena. Shaefer (1953: 227) argues, "in geography the major regularities which are described refer to spatial patterns, and hence geography has to be conceived as a science concerned with formulation of the laws governing the spatial distribution of certain features on the earth”. Moreover, quantification was justified by the shifts from individual understanding to general laws and from interpretation to prediction (Unwin 1992). That was how logical positivism had got ground in geography.

The starting point of positivism in investigating famine would be from the existing theories that were formulated on the basis of experiences and evidences. An assessment of previous studies, which specifically explored into the explanations of famine, has a paramount significance in various preliminary activities of a study such as stating the research problem, synthesizing the research questions (formulating hypothesis), designing research framework, and selecting appropriate methods of data generation and the techniques to analyze it. In what follows, attempt will be made to summarize and present few of the famine theories that have been serving as guides for research works on famine in the positivist tradition. A review of one case study that was inspired under the philosophy of positivism will be presented for illustration. 


\subsection{Theories of Famine in the Tradition of Positivism}

Although it seems practically difficult to claim that one theory is superior to others in addressing famine, various researchers have come out with a verity of theories to explain famine. Devereux (1993) examines some of them in his book Theories of Famine. Taxonomy of famine theory varies according to the interests of the authors, which are mainly influenced by disciplinary scope and ideological differences. Nonetheless, in this paper I adopted Devereux's (1993) grouping that presents famine theories under three main types: Food Availability Decline (FAD) Theories, Economic Theories, and Political Economy Explanations. A common feature of most famine theories would be their emphasis on identifying what causes hunger, which is the central concern of the positivistic approach.

\subsubsection{Food Availability Decline (FAD) Theories}

FAD theories are sometimes regarded as supply-side models as they pay much attention to factors that adversely affect food availability. The two main explanations of food shortage under FAD theories are demographic (population growth) and climatic (drought, flood or other hazards).

\section{a. Demographic (Population Growth) Theories}

The work of Thomas Malthus probably marks the first serious concern on the threat of rapid population growth as a cause of food shortage (famine). Malthus states that "population, when unchecked, increases in a geometrical ratio; subsistence increases only in an arithmetical ratio" (Malthus 1798:9). The central argument would be the superior power of population to expand must in general tend to be kept in check by requirement of food and other necessities whose production cannot be increased so rapidly. As a result, hunger and other forms of human poverty and misery are inevitable consequences of the pressure of population growth on limits of productive capacity (Millman and Kates 1990).

Malthus' theory is criticized in two ways. First, the theory fails to allow for technological improvements in agriculture, which would enhance agricultural productivity. Second, he did not foresee the transport and communication revolutions (Deveroux 1993). Despite this, Malthus' theory has still practical relevance to the situations of some countries such as Ethiopia, India, China and Indonesia. That is why those countries are still attempting to issue and implement the neo-Malthusian "restrictive population policies".

Karl Marx was another author who looked into the relationship between population and production, although his model is somehow specific to the context of capitalist mode of production. Marx disagreed with Malthus, finding the roots of hunger and other forms of human misery in relation to oppression and exploitation tied to the organization of production (Millman and Kates 1990). The main limitation of his argument is its lack of relevance across different socio-economic systems.

Ester Boserup (1965) has come out with a theory, which is contra-Malthusian. Her theory demonstrates the causal relationship between population growth and transformation of agriculture. Boserup sees population growth as a force favoring the adoption and diffusion of technological innovation that expands agricultural production, thereby reducing vulnerability to famine and food insecurity. She argues that the positive effect of population concentration is by making financially feasible investments in infrastructure 
(water and irrigation, energy and transport and improved production technologies) (Boserup 1965)

It is therefore possible to draw that a positivist famine research can be inspired on the basis of the theoretical framework of either Malthusian or Boserupian approaches in investigating the relationship between population size and famine.

\section{b. Climatic (Drought or Flood) Theory}

Drought or flood causes crop failure and can lead to famine in rain fed agricultural areas. Both scarcity and excessive water have adverse effects upon crop and livestock, which form the main source of livelihood for subsistence farmers. This is witnessed by many famine hazards that had killed millions of people in Sub-Saharan Africa and South Asian countries over several decades. For instance, the Ethiopian famines in 1958, 1973, and 1984 and 2002/2003 are mainly explained by drought and resultant crop failures. Harrison (1988) indicates twenty-one countries in Africa experienced severe drought during 1984-85, and this as much as anything was responsible for the widespread famine over the continent at that time. Drought manifests itself not only in reducing production but also through adverse effect that it brings about in terms of reducing rural employment and raising food prices on the market.

\subsubsection{Economic Theories (Demand-side Theories)}

An economic theory consists of two approaches of explaining famine: Food Entitlement Decline (FED) and Market failure. FED model is pioneered by Amartya Sen (1981) as an alternative method for the analysis of famine. His theory has brought about a shift of famine analysis from seeking explanations for the short supply to the identification of symptoms of the failure in demand. It suggests that food availability in the economy or in the market does not entitle a person to consume it, and famine can occur without aggregate availability decline. Sen presents few supporting evidences for his argument: the Bengal famine of 1943, the Ethiopian famines of 1973 and 1982, and the Bangladesh famine of 1974. He believes that it is access to food, which plays a crucial role in securing command over food, which is determined by source of entitlement to food. The four possible sources of entitlements are production-based, trade-based (exchange), own-labor, and inheritance and transfer.

One of the strong points of FED famine analysis approach is its potential capacity to identify which group of people will be affected by various threats to availability or access to food (Maxwell and Smith 1992). A famine researcher should bear this in mind while deciding on the unit of analysis. FED approach enables to investigate famine at household level.

Market failure approach is another economic way of examining famine, which views market problem from demand (pull failure) and supply (response failure) perspectives. Pull failure refers to people's lack of purchasing power, which is caused by poverty and can therefore be explained in terms of lack or collapse of exchange entitlements to food. Likewise, response failure can happen when market fails to meet an effective demand of people. 


\subsubsection{Political Economy Explanations}

There exist certain hypotheses, which have not yet been recognized to the status of fullfledged theories of famine, and regarded by some authors as general explanations to food shortage. These include ecological degradation, inappropriate development strategy, government policy, and war and civil strife. Ecological degradation as the cause of famine is, for instance, demonstrated by expansion of the Sahara desert into the arable land of Western Sudan, which makes people vulnerable to famine (Devereoux 1993). Dependency theorists argue that colonial and post-colonial relationship between poor countries in Africa, Latin America and Asia on one side and the rich capitalist countries of Europe and North America, on the other exacerbates poverty and famine. This is a good example of how inappropriate development strategy marginalizes the poor (Ghosh 2001). Famine in India during the late $19^{\text {th }}$ century and the 1940s rightly illustrates this issue. Lack of good governance also contributes for the occurrence of famine. Dreze and Sen (1989: 6) argue that "many famines in the world have actually arisen from and been sustained by inflexible government policies undermining the power of particular sections of the population to command food". Governments contribute to the happening of famine through four ways: inappropriate policies (Sahelian famines); failure to intervene (the Chinese famine of 1958 61, the Bangladesh famine of 1974, and the Ethiopian famine of 1974 and 1984); by-product such as civil war (Mozambique and Chad in 1980 and Somalia in 1990); malign intent or deliberate government creation of famine (Soviet Famine of 1933 and Dutch famine of 1944). All these explanations still remain as hypothesis calling for further research that can either verify or falsify them.

\subsection{Case Study: Determinants of Household Food Availability in Oromiya Zone}

A study was carried out in Oromiya Zone of Ethiopia to identify factors that affect the amount of per capita food available at household level in 1999 (see Degefa 2002). Food availability, which was estimated by mean per capita food available in calories, was taken as the indicator of food insecurity and food shortage. Household survey at three communities was a method to generate data from 180 households, 60 at each. As the study was carried out by employing the positivist approach, the following testable hypotheses were set.

I. Per capita food available in calorie increases with the increase of age of household head, education level of the household head, land holding size, fertility of farmland, total number of livestock, number of farm oxen and size of crop harvest. All variables are assumed to positively correlate with the food availability.

II. Per capita food available in calorie decreases with the increase of the household family size.

III. Per capita food available for households headed by male is greater than for femaleheaded households.

IV. Per capita food available is positively correlated with the utilization of modern farm inputs, namely chemical fertilizers, improved seeds, herbicides, pesticides, irrigation, 
extension services, farm credit and off-farm income. This means the food security situation of technological input user farmers is better than their non-user counterparts.

Attempt was made to examine the statistical association of seventeen factors with the food availability and to measure how far the variation of per capita food available (as dependent variable) is explained/predicted by those independent variables. The multivariate regression model is employed for this purpose. The results from the multiple regression models confirm the observations of cross-tabulations for the type and directions of the relationship of most of the independent variables with the per capita calorie available for consumption. The seventeen predictors explain about $28 \%$ of the variations of the food availability $\left(r=0.529\right.$ and $\left.r^{2}=0.28\right)$. The food availability variation with an ANOVA of F- ratio of 2.792 is found to be statistically significant. Among the independent variables the size of crop harvest, family size, age of head, use of irrigation and sex of the head were found to be the major determinants of food availability.

Food availability has shown an increase with the education and age of the head. The impact of education on household food production might be through promoting awareness about the possible advantages of modernizing agriculture by technological inputs and diversifying household incomes, which in turn enhance household food supply. Likewise, the higher the age of the head, the more stable the economy of the farm household. Aged people have also relatively rich experiences of social and physical environments. Moreover, aged people are expected to have better access to land than the young heads. Per our expectation and in line with the descriptive cross tabulation, the per capita food availability of male-headed households is found to be greater than that of female-headed households.

Having a large number of livestock and possessing fertile farmlands were found to enhance household's food security situations. The positive correlation of these variables with food availability rightly confirms our hypothesis. This is consistent with the assumption that per capita food available decreases with the increase of the household members. This clearly shows that large family size has got more implication for food consumption than for labour supply to boost agricultural production.

The regression results show surprisingly the decline of food availability with the increase of the number of farm oxen possession and land holding size. This does not go with existing theories as well as the initial assumption. An inverse relationship may be explained by the crop damage facing the studied farm households during the year under consideration, and the big loss was for farmers with large land holdings and those with better access to draft power. Because of this fact, home production was not the major source of food for consumption for most households in the study year.

Our hypothesis of the relationship between the availability of food and the technological inputs application is found to be mixed, that is, positive relationship for some as expected, and negative correlation for others. The utilization of farm credits, improved seeds, herbicides and irrigation has, indeed, enhanced the volume of food at the household level. This means the inputs could serve, to some extent, the intended purposes. On the other hand, per capita food availability has declined for the farmers who utilized commercial fertilizers and insecticides as well as for the farmers who had the advantage of getting access to off-farm employment and extension services. Depending on this observation it appeared 
difficult to reach a sound conclusion about the relationship between the size of crop harvest and the inputs. For one thing, other factors such as drought and pests might have undermined the possible contribution of those modern inputs. Secondly, considering the amount of fertilizers and the insecticides used and the size of income obtained from nonfarm income may change the direction of relationship with food availability.

What can a famine researcher learn from this case study in terms of the positivist approach? The important thing here would be the possibility to identify environmental and human explanations to famine. Variables must be carefully selected while formulating a research framework and measured at the stage of data generation. A well-designed household survey preceded by pilot study can enable to generate quantifiable data for this purpose. The main drawback, however, would be that the observation tends to be shallow as a detailed treatment of the relationship between famine across each factor is practically impossible.

Before concluding this section, let me mention other points of critique against positivism, which in part contributed for the emergence of other schools of thought in geography. First, positivists underestimate the relationship between theory and observation. For instance, in the case study discussed above, if we rerun a multiple regression, after omitting the interrelated variables that are expected to have co-linearity, we will obviously end-up with different results. Second, the mathematical language that is applied in positivism disregards social and ethical questions, and fails to recognize that spatial patterns and processes which are reflected in perceptions, intentions, and actions of human beings. Third, positivists' belief in 'value-free' and 'objectivity' is not acceptable for it attempts to separate the observer from the observed (Cloke et al. 1992).

\section{Humanism and Understanding Famine}

One of the main criticisms of the logical positivist tradition in geography was that the laws and models developed during the 1960s failed to sufficiently address individuals and the human condition. This led many geographers (Entrikin 1976; Tuan 1976; Buttimer 1976) to turn to the philosophical approaches of humanism. In humanism, the epistemology is that knowledge is obtained subjectively in a world of meanings created by individuals, and its ontology is that what exists is that which people perceive to exist. Therefore, humanists are concerned with reflection and understanding, as opposed to the logical positivist goal of explanation. Geographers adopted many different humanist perspectives in the 1970s. Most of these were underlain by the philosophies of 'phenomenology', 'existentialism' and 'idealism'.

In Tuan's (1976:266) words, "humanism provided geographers with the central task of reflecting upon geographical phenomena with the ultimate purpose of achieving a better understanding of man and his conditions". Tuan (1976:267) drew the following contrasts between scientific and humanistic approaches to the subject: "scientific approaches to the study of man tend to minimize the role of human awareness and knowledge. Humanistic geography, by contrast, specifically tries to understand how geographical activities and phenomena reveal the quality of human awareness". 
For Entrikin (1976:616) the humanist approach was reaction by its proponents to "an overly, objective, narrow, mechanistic and deterministic view of man”, with the appellation 'humanistic' reflecting their concern with "the aspects of man which are most distinctively "human": meaning, value, goals, and purposes". The seminal work of de Waal (1989) in Darfur typifies famine research that relied upon humanism. He attempted to understand famine from the perspective of rural people who suffered from it. De Waal (1989: 1) says "I am trying to change the way that we, that is the affluent world, understand famines in the poor countries... a change in the understanding should lead to a profound change in the way in which governments and relief agencies respond to the threats and occurrences of famine”.

In broad sense, humanist approaches emphasize individuality and subjectivity rather than replicability and truth. Nonetheless, there exists a lack of agreement over the methodology to be employed among the variant philosophies of humanism. Hence, it is important to briefly look into famine through the lens each of them proposes.

\subsection{Phenomenology and Famine}

Among the major humanist traditions, it was the phenomenology of Husserl ${ }^{1}$ that first attracted the attention of geographers in the early 1970s. The key attraction of phenomenology was its rejection of the assumption of objectivity, which enabled logical positivists to ignore the preconceptions and subjectivity upon which their laws and models were based (Unwin 1992:147). To Husserl, the distinction between object (world) and subject (humans) was problematic. He sought to overcome this dualism and to provide a powerful, rigorous and alternative philosophy to positivism so far lacking in humanist thought (Cloke et al. 1992). Phenomenology was designed to disclose the world as it shows itself before scientific inquiry, as that which is pre-given and presupposed by the sciences. It seeks to disclose the original way of being prior to its objectification by the empirical sciences' (Pickles 1985: 3). Pile (1993: 24) describes phenomenology as a “people-centered form of knowledge based in human awareness, experience and understanding... the study of, and conscious reflection on, the meaning of being human, of being located in time and space”.

According to Johnston (1986:62-63), phenomenology is based upon three assumptions: "first, that people should be studied free of any preconceived theories of suppositions about how they act; second, the search for understanding of the nature of an act is the goal of social sciences, rather than explanation; third, that for the people the world exists only as a mental construction, created in acts of intentionality". An element is brought into individual's world only when he or she gives its meaning because of some intention towards it.

Phenomenological studies of famine reconstruct the victims' viewpoints about the problem. In order to have an opportunity to observe and appreciate the situations and conditions for an in-depth understanding of the process, the researcher needs to stay in the community where famine happened. Among the several research questions to be

${ }^{1}$ Edmund Husserl (1859-1938) contributed for the development of phenomenology arguing that because positivists ignored the questions of their own involvement in the research process, they could not really know the world. 
investigated under the tradition of phenomenology may include: What is meant by famine from the viewpoints of people experiencing it? What do the victims feel while facing the problem of hunger? Do the victims know and are they able to identify what induced famine? Do they have their forecasting mechanisms for the situation of famine? How does famine disrupt peoples' livelihoods, and social relations and networks? What copping mechanisms do people practice at different stages of hunger periods, both at household and community level? What do the victims think, should be done to prevent famine? Qualitative methods, specifically participant observations, ethnography and case-studies will help to generate data enabling to answer these questions.

Although I feel that the study was not fully phenomenological in its approach, I decided to cite the observation from the community assessment at 21 villages of South Wello and Oromiya zones during the 1999 Ethiopian famine. The main purpose of that specific study undertaken by Yared et.al (2000) was to assess the perceptions of community members regarding famine and food insecurity. The victims were able to express their own impression on the suffering from hunger that affected their community. People at Tabsit and Mariye described the situation of famine facing them in 1999 as follows.

People in Tabsit reported that less food was presently available in local markets compared to past food shortages. Grain prices have been rising, as well as the prices of salt, sugar, and other commodities. In contrast, livestock prices have sunk. The men's focus group noted that livestock prices have been largely depressed for five years, and that they dropped steeply since last year. In comparing the present situation with the past, both men and women in Tabsit observed that grains are scarcer.

In Mariye, the severe food shortages reportedly caused some people to leave the community in search of food, work and relief. The officials stated that whether the rains come or not, relief was urgently needed, or deaths would soon follow. But focus groups claimed that grain prices had risen considerably, exceeding the levels experienced in the 1984 famine. They also stated that livestock prices had fallen rapidly (Yared et al. 2000:26).

\subsection{Existentialism and Famine}

Existentialism is based on the notion that reality is created by the free acts of human agents, for and by themselves. According to Buttimer (1976), its fundamental concern is 'the quality of life in everyday world'. As such, there is no single essence of humanity, but rather each individual creates and forges his own essence from existence. Existentialism focuses upon how individuals come to create and place meaning to their world and how they subscribe values to objects and others (Kitchin and Tate 2000). The researcher's job is to seek to understand the processes of making the world meaningful as it is these processes by which we come to know and behave in places.

Existentialism can deal with famine from historical viewpoints. One way of doing this would be reconstructing back regarding previous famines from the elderly as to when the major famines occurred, and their consequences upon people (in terms of deaths, out 
migration, family disintegration, etc), upon economy (asset loss, livestock sell and deaths), and upon environmental elements such as natural vegetation, wild life, water points and so on.

Another instance of existentialism research in geography would be to understand famine in relation to land-use changes and diminishing holding sizes per household. One of the driving forces for the subsistence farmers' inability to produce sufficient food grains for home consumption has been the lack of adequate land holding size partly due to accelerated population growth. Looking into the shrinking of individual holding over time and changes in overall land-use patterns over certain periods attracts famine researchers. Expansion of farm lands towards marginal areas manifests itself in declining yields per unit area, on one hand, and degradation of land resources (soils, vegetation, water, etc), on the other, both of which have direct implications for poverty and food security.

\subsection{Idealism and Famine}

Whereas existentialism focuses upon realty as being, idealism views reality as a construction of mind (Unwin 1992). Thus idealism holds that the world can only be known indirectly through ideas with knowledge based on subjective experiences. As such, idealism seeks to explain rational actions through the understanding of the thoughts behind them. Studies of famine inspired under idealism will purely rely upon the study of perception and thoughts of people experiencing it. It is assumed that their behavior and action during periods of hunger are explained by what they think rather than what are being observed to exist in reality. Therefore the investigation can focus on two important issues. The first would be assessing the famine victims' perception of their own hunger. Second, understanding how the famine victims see themselves in relation to the rest of the society. Thus, the appropriate methods of data collection can be qualitative, in particular in-depth interviews with the people facing hunger, and through ethnography.

\section{Structuralism: Understanding Famine as an Outcome of a Constraint of Structure}

One of Habermas' central concerns in knowledge and human interests was to develop understanding of the connections between knowledge and action (Unwin 1992). This corresponds with what Habermas calls the critical sciences and the philosophy of stucturalists in geography. The central feature of structuralist approaches is an axiom that explanations for observed phenomena must be sought in general structures which underpin all phenomena but are not identifiable within them; the explanation cannot be produced through empirical study of the phenomena alone (Johnston 1983: 87). Thus, structuralists believe that the world of appearances does not necessarily reveal the world of mechanisms. To investigate the latter it is necessary to have an ontology which states that what really exists (i.e. the forces creating the world, or the structures) cannot be observed directly but only through thought. The methodology in structuralism involves the construction of theories, which can account for what is observed but which cannot be tested for their veracity because direct evidence of their existence is not possible. 
Mesfin’s (1984) study of Ethiopian famines between 1958 and 1977 blames the structural constraint to be the driving force for food shortage. The Imperial government and the Derg rural development policies were very defective in terms of minimizing the effects of environmental calamities such as drought and land degradation. Emphasizing on this issue Mesfin states "an agricultural population must first be made vulnerable to famine by the product of the socio-economic and political forces before any diverse natural factor initiates the process of food shortage that inevitably leads to famine" (Mesfin 1984: 14-15). There exists a variety of philosophies within structuralism the main ones being Marxism, Realism and Feminism.

\subsection{Marxism and Famine}

Marxism is a system of thought, which claims that the state through history, has been a device for the exploitation of the masses by a dominant class and that class struggle has been the main agent of historical change (Peet and Lyons 1981). Marxists argued that positivism failed to recognize the economic and political constraints imposed upon spatial patterns by the way in which society worked. Further they suggested that positivistic methods restricted analysis to how things actually seemed to be, rather than considering how they might be under different social conditions (Cloke et al. 1992). A Marxist geography seeks to identify how social relations vary over space and time in order to reproduce and sustain the modes of production and consumption, to suggest alternative features, and to offer political resistance.

An investigation of famine within the Marxist tradition can be undertaken at two important geographical scales: national and household. Historical evidences clearly show that famine mainly threatens the people in developing (poor) countries. Famine becomes one of the several manifestations of a nation's underdevelopment ${ }^{2}$, which partly results from the exploitation by developed capitalist countries. In this regard, it is possible to explore whether the persistence of famine in a country is largely caused by internal (indigenous) or by external (exogenous) factors, specifically the type of economic relationship it has with the advanced capitalist countries.

Famine that occurs in a country or region inflicts the marginal segments of a population. At household level, the poor are obviously the most vulnerable to famine and food insecurity. This is because the systems in most developing countries disempower the poor both economically and politically. An extremely low wage for those who have the opportunity to get job, and unemployment would be among the economic challenges facing the poor. Poverty alleviation, therefore, means how to empower the poor by improving their living conditions and enhancing their participation in decision-making processes at local level. Hence, the famine researcher can focus on the empowerment of the poor.

\subsection{Realism and Famine}

Realism searches for explanation, with which it holds common feature with positivism. Nonetheless, while realists believe that there is a 'real' world that exists independently of our senses, perceptions and cognitions, in contrast to positivists, realists argue that the social

\footnotetext{
${ }^{2}$ See Adere Gunder Frank's Development of Underdevelopment in Ghosh (2001)
} 
world does not exist independently of knowledge and that this knowledge, which is partial or incomplete, affects our behavior (May 1993).

In the realist tradition, the task of research 'is not simply to collect observations but to explain these within theoretical frameworks which structures people’s actions’ (May 1993: 7). Thus, realists are concerned with the investigation of the underlying mechanisms and structures of social relations, and identifying the building blocks of reality. Realism is concerned with the identification of how something happens (casual mechanisms) and how extensive a phenomenon is (empirical regularity) (Unwin 1992). Realists want to find out what produces changes, what makes things happen, what allows or forces changes (Sayer 1985:163).

According to realism, the recurrence of famine is due to lack or partial knowledge and understanding of what produces it. This would lead to the formulation of unsound policies and strategies to help curb out the problem. The following can be among the few research questions that can be investigated with in the framework of the philosophy of realism: What are the root causes of famine? Is it happening due to physical environment related factors, the disparities in access to resources or inadequate social and economic infrastructure? What public policies will help overcoming these constraints?

\subsection{Feminism and Famine}

Feminism is a relatively new approach that started to grow in geography since the 1980s. The feminist approach critiques all forms of geographical inquiries on two grounds. "First, feminists have argued that geographical research largely ignores the lives of women and the role of matriarchy in society. Second, they have criticized the ways in which research is conducted, arguing that knowledge is predominantly produced by men and as a result represents men's views of the world" (Kitchin and Tate 2000).

In response to this, feminist geographers have adopted an epistemology which challenges conventional ways of knowing by questioning the concept of "truth, validating alternative sources of knowledge such as autobiographical accounts and subjective experience, and acknowledging the non-neutrality and power relations within research" (Women in Geography Study Group 1997). Feminist methodology is, therefore, characterized by search for mutual understanding between researchers and the researched (Katz 1994). It focuses thought upon four issues: ways of knowing, ways of asking, ways of interpreting, and ways of writing.

A Feminist approach can be adopted in undertaking famine research in a number of ways. Instances are given here at two scales: household and intra-household levels. At the former level, we can start from the selection or sampling of households to be investigated. Female-headed households become the main subject of study or if necessary attention will be given to balance gender representation in terms of the proportion of the subject to be investigated. The second concern in connection with famine would be to look into who is more vulnerable to famine from female-headed and male-headed households. Identifying this would lead us to proceed with the inquiry of explanations for disparity. Does famine happen because of inequalities among households in terms of access to production resources such as land, labor, farm oxen, credit, etc? 
Feminists can study intra-household factors of food security and famine. In the first place, it is possible to consider gender bias while studying a single household. Most nonfeminist studies tend to generalize household food security situations simply by considering the impression of men, whereas in reality they are the women who play considerable role in household food rationing over a period of food scarcity. The second important issue would be the power relationship between husband and wife in decision-making on expenditure and asset disposal during famine crises. Third, there exists gender disparity in migrating out of famine prone areas. A research in Northwestern Ethiopia in this regard found out that men immigrate to other areas leaving behind women along with their children. This puts an extremely big burden on them, due to the fact that whether they receive remittances from husbands or not, they are expected to feed the family (Degefa 2000).

A recent study by Gladwin et al. (2001) examines how to promote female-headed household (FHHs) food security in Africa through multiple livelihood strategies. They argue that efforts to increase women's food production over several decades have not been effective enough to pull households out of food insecurity and poverty. Gladwin et al. (2001) suggests, "governments in Africa should look for ways to improve returns to women farmer's resources in broader context and facilitate women's cash cropping, income generating activities and agricultural labor". They derived this conclusion partly from the land-scarce FHHs case study in Zomba, Malawi, which was described as:

FHHs tend to be in the more impoverished category, and land scarce situations are the most common and pressing scenario in Africa today... Malawi is the sixth poorest country in the world with $41 \%$ of the rural population $(16.4 \%$ FHHs and $24.6 \% \mathrm{MHHs}$ ), operating $<0.5$ ha of land and producing enough food to last 3-4 months of a year... It is a household comprised of 3.5 consumption units requiring the consumption of $700 \mathrm{~kg}$ of maize a year. This household cultivates 0.29 ha, with 0.25 ha under local maize and 0.04 ha under groundnuts. Using no fertilizers or hybrid seed, this FHH produces only $217 \mathrm{~kg}$ of maize (31\% of its consumption requirements), and $15 \mathrm{~kg}$ of groundnuts. After three and half months or longer if they stretch consumption, the family will run out of food. The rest of the year's food supplies have to be made up from off-farm income opportunities, most probably ganyu, an informal piecework labor paid in maize (Gladwin et al. 2001:181- 182).

This case study illustrates how female households are more vulnerable to famine and food insecurity, mainly due to lack of access to the main production factors, such as land and modern inputs, as well as lack of access to non-farm income generating opportunities.

The observations from the study can serve as hypothesis for replicating research in other African countries.

\section{Concluding remarks}

The discussions have shown that it is difficult to reach a conclusion as to which single approach enables to deal with famine best. The selection of appropriate approach, above all, 
depends on the goal of a research to be carried out. If the objective of the project is, for instance, to seek explanation for famine there is no question about the appropriateness of positivism, while if the purpose would be to have deeper understanding of the phenomenon of famine and processes humanist philosophies become the better approaches to lay the foundation of a research upon. In order to investigate famine in connection with poverty alleviation through empowering the poor and other marginal and vulnerable segments of a population such as women, aged, disabled and children employing structural approaches will be advisable.

However, it was learnt that famine is a multi-dimensional socio-economic problem, which requires an in-depth understanding as well as investigating into its root causes so as to come up with sound policy implications towards preventing it. This may call for a research project that goes across different approaches. Therefore, depending on the purpose of a study to be attained, it seems possible to design a research project in which various approaches can be mixed to answer different research questions whereby quantitative and qualitative research methods can be adopted to address the problem. Basically, this does not mean that a researcher should at the same time hold the position of positivist, humanist nor structuralist. The possible solution can be to design a famine research project to be dealt with by researchers with diversified philosophical beliefs. The overall outcome in terms of knowledge, although sometimes incompatible, can contribute significantly in preventing and eradicating famine.

\section{Acknowledgement}

I would like to thank Dr. Mendida Barkessa for his help in editing the language of the manuscript.

\section{References}

Alamgir, M. 1980. Famine in South Asia: The Political Economy of Mass Starvation. Cambridge: Mass.

Boserup, E. 1965. The Conditions of Agricultural Growth. New York: Aldine.

Buttimer,A. 1976. "The Dynamism of Life world. Annals of the Association of American Geographers, 66(2), 277-92.

Chalmers, A.F. 1982. What is This Thing Called Science? Queensland: University of Queensland Press.

Cloke, P., Philo, C. and Sadler, D. 1992. Approaching Human Geography: An Introduction to Contemporary Theoretical Debates. London: Paul Chapman.

Curry, B. 1978. "The Famine Syndrome: Its Definition for Relief and Rehabilitation in Bangldesh”. Ecology of Food and Nutrition, 7(1), 87-98.

Dando, W. 1980. The Geography of Famine. London: Edward Arnold.

Degefa Tolossa. 2000. Causes to Households Seasonal Food Shortage in South Gonder. Unpublished Research Report. 
Degefa Tolossa .2002. Household Seasonal Food Insecurity In Oromiya Zone Ethiopia: Causes. Social Science Research Report Series Number 26. Organization for Social Science Research in Eastern and Southern Africa. Addis Ababa: OSSREA.

Degefa Tolossa. 2005. Rural Livelihoods, Poverty and Food Insecurity in Ethiopia: A Case Study at Erenssa and Garbi Communities in Oromiya Zone, Amhara National Regional State. Published Dissertation for the Degree of Doctor of Philosophy, Norwegian University of Science and Technology (NTNU), Faculty of Social Sciences and Technology Management, Department of Geography. Trondhiem.

Devereux, S. 1993. Theories of Famine. New York: Harvester Wheatsheaf.

De Waal, A. 1987. "The Perception of Poverty and Famine”. International Journal of Moral and Social Studies, 2, 251-62.

De Waal, A. 1989. Famine That Kills: Darfur, Sudan, 1984-1985. Oxford: Clarendon Press.

Dreze, J. and Amartya S. 1989. Hunger and Public Action, Oxford: Clarendon Press.

Entrikin, J.N. 1976. “Contemporary Humanism in Geography”. Annals of the Association of American Geographers, 66(4), 615-32.

Getachew Diriba.1995. Economy at the Cross Road: Famine and Food Security in Rural Ethiopia, A.A: Care International in Ethiopia.

Ghosh, B.N. 2001. Dependency Theory: Revisited. Aldershot: Ashgate.

Gladwin, C.H, Thomson, A.M, J.S. \& Peterson, A.S. 2001. “Addressing Food Security in Africa via Multiple Livelihood Strategies of Women Farmers”. Food Policy, 26 (3), 177-207.

Harvey, D.1969. Explanation in Geography. London: Edward Arnold.

Harrison, G.A. (ed.) 1988. Famine. Oxford: Oxford University Press.

Holt-Jensen, A. 1999. Geography: History and Concepts. London: SAGE Publications.

Johnston, R.J. et.al., 2000. The Dictionary of Human Geography. Oxford: Blackwell Publisher.

Johnston, R.J. 1983. Philosophy and Human Geography: An Introduction to Contemporary Approaches. London: Edward Arnold.

Johnston, R.J. 1986. Philosophy and Human Geography: An Introduction to Contemporary Approaches, Second edition. London: Edward Arnold.

Johnston, R.J. 1991. Geography and Geographers: Anglo-American Human Geography since 1945. London: Edward Arnold.

Katz, C. 1994. "Playing the Field: Questions of Fieldwork in Geography”. The Professional Geographers, 66 (1): 67-72.

Kitchin, R. and Nicholas.J. T. 2000. Conducting Research into Human Geography: Theory, Methodology and Practice. London: Pearson Education.

Malthus, T.R. 1798. 'An Essay on the Principle of Population', in Wrigley and David Souden (eds.) The Works of Thomas Robert Malthus, Volume 1. London: William Pickering.

Maxwell, S. and T.R. Frankenberger. 1992. Household Food Security: Concepts, Indicators, Measurments, A Technical Review. Rome: UNICEF and IFAD.

May, T. 1993. Social Research: Issues, Methods and Process. Buckingham: Open University Press. 
Mesfin Wolde Mariam. 1984. Rural Vulnerability to Famine in Ethiopia, 1958-1977. New Delhi: Vikas Publishing House PVT.LTD.

Millman, S. and Robert W.K. 1990. “Toward Understanding Hunger,” in Newman, L.F et.al., (eds.) (1990) Hunger in History: Food Shortage, Poverty, and Deprivation, Cambridge. Mass: Basil Blackwell, 13-24.

Newman, L.F. et.al., (eds.) 1990. Hunger in History: Food Shortage, Poverty, and Deprivation. Cambridge: Basil Blackwell, 1-12.

Peet, R. 1998. Modern Geographical Thought. Oxford: Blackwell.

Peet, R.J. and Lyons, J.V. 1981. Marxism: Dialectical Materialism and Geographic Relations, in Harvey, M.E and Holly (eds), Themes in Geographic Thought. London: Croom Helm, PP. 187-206.

Pickles, J. 1985. Phenomenology, Science and Geography: Spatiality and Human Sciences. Cambridge: Cambridge University Press.

Pile, S. 1993. "Human Agency and Human Geography Revisited - A Critique of New Model of the Self”. Transactions of the Institute of British Geographers, 18 (2). 122139.

Pinstrup-Andersen, P. and Rajul Pandya-Lorch. 2001. The Unfinished Agenda: Perspectives on Overcoming Hunger, Poverty, and Environmental Degradation. Washington, D.C:IFPRI.

Rangasami, A 1985. Failure of Exchange Entitlement Theory of Famine: A Response, Economic and Political Weekly, XX, 20-21.

Sayer, A. 1985. Realism and Geography, in Johnston, R.J (ed.), The Future of Geography. London: Methuen.

Schaefer F.K 1953. "Exceptionalism in Geography: A Methodological Examination”. Annals of the Association of American Geographers, 43, 226-49.

Sen, A.1981. Poverty and Famine: An Essay on Entitlement and Deprivation. Oxford: Clarendon Press.

Tuan Yi-Fu. 1976. "Humanistic Geography”. Annals of the Association of American Geographers, 66(2): 266-76.

Unwin, T. 1992. The place of Geography. New York: Longman Group.

Watts, M. 1983. Silent Violence: Food, Famine and Peasantry in Northern Nigeria. Berkeley: University of California Press.

Women in Geography Study Group. 1997. Feminist Geographies: Explorations in Diversity and Difference. Harlow: Longman.

Yared Amare, Yigremew Adal, Degefa Tolossa, Castro,A.P. and Peter. D. L. 2000. Food Security and Resource Access: A final Report on the Community Assessment in South Wello and Oromiya Zones of Amhara Region, Ethiopia. A.A: BASIS/IDR. 